\title{
Does My Stigma Look Big in This? Considering Acceptability and Desirability in the Inclusive Design of Technology Products.
}

\author{
Jo-Anne Bichard ${ }^{1}$, Roger Coleman ${ }^{1,}$ Pat Langdon ${ }^{2}$ \\ ${ }^{1}$ Helen Hamlyn Centre, Royal College of Art \\ Kensington Gore, London, UK \\ ${ }^{2}$ Engineering Design Centre, University of Cambridge \\ Department of Engineering, Trumpington Street, Cambridge, UK \\ \{roger.coleman, jo-anne.bichard@rca.ac.uk; pml24@eng.cam.ac.uk
}

\begin{abstract}
This paper examines the relationship between stigmatic effects of design of technology products for the older and disabled and contextualizes this within wider social themes such as the functional, social, medical and technology models of disability. Inclusive design approaches are identified as unbiased methods for designing for the wider population that may accommodate the needs and desires of people with impairments, therefore reducing 'aesthetic stigma'. Two case studies illustrate stigmatic and nonstigmatic designs.
\end{abstract}

Keywords: Inclusive Design, social inclusion, stigma, aesthetic design

\section{Introduction}

This paper aims to explore possible 'stigmatic' aspects of products that are designed to aid older people and people with disabilities. Its central question asks if it is possible for 'stigmatic' aspects to be identified in early stages of design and subsequently designed out. The paper will begin by addressing the importance of functional need and aesthetic quality. It will then assess the various models that can be seen to be determining certain design aspects. Using perspectives from wider social criticism the paper will illustrate how products can project wider social meaning concerning the ability of their user. Case studies of two particular products will be assessed to highlight where aspects of the design could be considered to continue stigmatising. Counter to this, another case study illustrate how an inclusive design approach eliminated such aspects.

\section{Stigma}

Stigma is defined in the Chambers English dictionary 'as a brand: a mark of infamy: a disgrace of reproach attached to any one'. Many disabled and older people identify 
their age and disability as being 'stigmatising' to the extent that they evoke negative responses. In his groundbreaking work Stigma Erving Goffman [1] proposes that stigma is not based on the functional limitations of a person's impairment, but rather the societal and social responses to disability. Recent UK legislation such as the Part 3 of the Disability Discrimination Act (DDA) attempts to target certain aspects of stigma by legally enforcing wider social inclusion of disabled people in areas such as access to the built environment. Yet whilst the act can determine the placing of a ramp, or access to suitable toilet facilities it does not include products that may be used within these public spaces. Bichard et al [2] have demonstrated that within accessible toilets, the door width may be adequate for most users of wheelchairs, but the soap dispenser maybe unusable for people with manual dexterity impairments.

For the purpose of this paper, stigma is considered an attitude brought about by a product or environment that emphasises physical, sensory or cognitive impairment as a result of birth, life course and or ageing. This impairment results in a loss of mobility and requires the use of products to assist or intervene.

\section{From Stigma To Aspiration; The Case Of Glasses}

Pullin [3] notes that in 1930's Britain, the National Health Service (NHS) prescribed spectacles to people with visual impairments that could be assisted by this technology. Spectacles were defined as 'medical appliances', and their wearers as 'patients'. In wider social life the wearing of NHS spectacles was considered to cause social humiliation and to be stigmatising. Initially NHS glasses were, as a medical product, believed to not need to be styled, but to provide 'adequate' function. By the 1970's the importance of styling had been acknowledged by the government (financers of the NHS), yet the medical model of sight impairment, to be corrected by functional spectacles, remained the dominant design discourse. Yet within this period, the design of glasses was taken up by the private sector, which offered more fashionable choice in glasses to those who could afford them [4]. By 1991, the design press had announced that eyeglasses have become stylish' [5]. Today, eyeglasses are available on most high streets, and sales records estimate that up to $20 \%$ of some brands are purchased with clear non-prescription lenses. Pullin proposes that the wearing of glasses has become aspirational opposed to stigmatising.

\section{Medical and Social Models of Disability}

All people operate within a range of abilities and are able to do different things at different ages. Ability is therefore a relative concept; relative that is to the abilities considered to lie within 'normal' ranges of behaviours for a person at a particular chronological age. Set within this context, disability becomes synonymous with deviation from the normal. The World Health Organisation [6] defines 'impairment', as a loss or abnormality of psychological, physiological or bodily structure or function. 'Disability' then refers to any limitation or lack of ability resulting from impairment, when performing an activity in the manner or within the range 
considered normal. These definitions imply a causation, whereby impairments cause disabilities.

However, this causation is not accepted uncritically. Many disability activists take issue with the implication that the disabled body is not normal and that disabled people are either patients with a medical condition that needs to be treated or victims of personal tragedy that need to be looked after. Activists therefore offer alternative definitions of disability, based on the assertion that disability is primarily a disadvantage or restriction imposed by a society that pays little or no attention to the needs of people with impairments, resulting in disabled peoples exclusion from mainstream social life. This makes disability an issue of social justice and inclusion.

These diametrically opposed positions are associated, respectively, with the 'medical' and the 'social' model of disability. The medical model assumes that disability is caused by an impairment, which then becomes the focus of attention. The medical approach seeks to ameliorate or cure the impairment and, by so doing, to reduce or eliminate the disability. The danger in this approach is that people are reduced to stereotypes defined by their disability. At the same time, the individual becomes the focus of change and society is absolved of the responsibility to ensure that disabled people's rights are safeguarded.

The social model asserts that whilst individuals may have impairments that may or may not require medical treatment, this need not prevent disabled people from being able to live a 'normal' and fulfilling life. Rather, it is society's unwillingness to devote enough resources to ensure that they do, which is the root cause of social exclusion. The social model points to environmental barriers, poor employment protection, inadequate civil rights legislation and so on, that prevent disabled people from enjoying the same advantages as non-disabled people. This view stresses the importance of broader attitudinal and environmental factors in shaping disabled people's lives arguing, in effect, that disability is socially produced.

Yet these two opposed models have both been criticised for selectively emphasising different aspects of disability; the medical model for ignoring social values and attitudes and the social model for denying the debilitating effects people experience as a result of impairment. A third position, the 'bio-social' model attempts to reconcile medical and social positions by proposing that the make up of the human body affects an individual's ability but at the same time who or what is defined as disabled depends on social attitudes and values. Imire and Hall [7] note, "impairment is usually collapsed into a series of general and chaotic categories, such as vision, mobility and hard-of-hearing, which do little to reveal the complexities of impairment. Indeed, impairment is neither fixed nor static, or confined to any particular part of the population. It can be temporary or permanent, debilitating or not; in short, it is a contingent condition dependent on circumstances" (ibid, 2001; 35).

Bio-social perspectives therefore begin by acknowledging both the complexity of impairment - for example, there is no agreed definition of impaired vision and every vision impaired person's experience of sight loss is unique - and the diversity of social responses to impairment, which can range from empathy and inclusion to intolerance and ostracism. The richer framework afforded by the biosocial model allows the issue of multiple disability to be addressed, thus providing a more holistic alternative to the stereotyped accounts based on single-issue disability. For example, studies of vision impaired adults found that over half of all those consulted had additional major health problems in addition to serious sight loss, and this figure approached nine out of ten among older vision impaired people [8], [9]. Multiple 
disability is therefore a far more challenging issue for design than that of making products and environments more accessible for people with reduced mobility as it requires a more complete understanding of the circumstances under which products and environments are experienced as disabling [9].

\subsection{Case study 1 An Example of stigmatic Design for Impairment}

In an audit of 101 accessible toilet facilities, Bichard et al [2] found that the toilet soap dispenser could be considered functionally inaccessible to users in $66 \%$ of facilities. In the majority of cases, the inaccessibility of the soap dispenser was primarily due to a choice of aesthetic over function (fig 1). In contrast, soap dispensers that provided adequate function, displayed an aesthetic in line with an object that 'would not look out of place in a hospital' and therefore reflected the medical model of disability (fig 2).

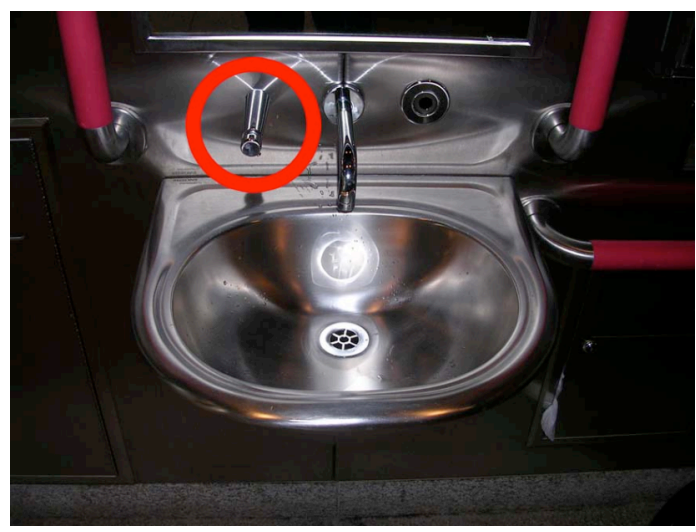

Fig 1. Integrated soap dispenser, reflecting aesthetic over function. Bichard 2005 / Vivacity 2020.

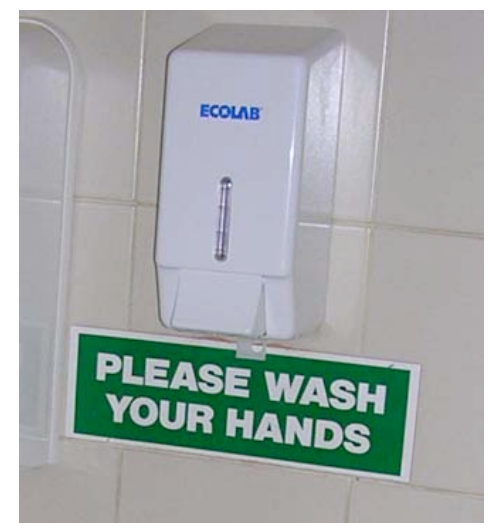

Fig 2. Soap dispenser reflecting a 'medical model' aesthetic. Bichard 2005 / Vivacity 2020 


\section{Technology and Disabled People}

Seldon, [10] argues that 'technology is not neutral... [but] is created by the same oppressive society that turns those with impairments into disabled people'. Davies [11] finds that technology is 'produced amidst conflicting social relations and thus holds the possibility of being a tool for liberation as well as for social control'.

Finkelstein[12] and Oliver [13] report that many disabled people are often excluded from mainstream technologies, which has lead to wider exclusion from the employment market. Whilst Illich [14] argues that whilst everyone is now dependant on some form of technology, the 'technological fixes' aimed at people with disabilities may discount any alternatives. Other commentators express concern that technologies specifically aimed at disabled people can be instruments of oppression as well as emancipation [13], [15].

\subsection{Assistive Technology}

Cowen and Turner-Smith [16] define Assistive Technologies (AT) as 'any device or system that allows an individual to perform a task that they would otherwise be unable to do, or increases the ease and safety with which the task can be performed'. Assistive technologies have a long and varied history that includes the development of the wheelchair to recent developments in electronics including sensors, robotic devices and remote controls. New developments are currently developing in the form of networked assistive technologies built into the home ('smart' technology), and telecommunications allowing medical care and health monitoring within the home. Newell [17] argues that AT and mainstream technologies are largely considered separate market segments, with AT principally directed at 'short term recuperation from injury or illness, or long-term functional support'. As such, design of AT products have similarly followed the 'market' and hence are largely 'health/ rehabilitation in flavour' and follow the medical model of disability.

Such specialised 'equipment' is usually costly to develop, especially for what is often perceived as a limited market. Newell proposes that to continue to follow a medical model within the design of AT is to miss out on a potential market of increased demographics of impaired mobility (be it from ageing or increased life spans of people with disabilities).

In an analysis of the acceptability of AT, McCredie \& Tinker (2005) [18] found that many AT products were used to accomplish everyday tasks. Research participants warmly recommended a portable device for hearing impairment that amplified sound and flashed when the doorbell rang. A participant with visual impairments commented on how a magnifier had changed her life. Yet, such ATs can be considered the equivalent of the ramp outside a stepped entrance, an afterthought to the design of a product (a suitable doorbell for hearing impaired, inaccessible font size). They further [18] note that the most important aspect of AT was that it worked properly, was reliable and safe. Yet other studies of ATs have found that the aesthetic aspect plays an equally important role. Hanson [19] found that AT 'add-ons' for visually impaired users of computers tended to be aesthetically displeasing within the domestic environment. One respondent commented that they now hid their 
computers out of social areas to avoid visitors seeing their 'special' equipment, effectively feeling stigmatised by the need to use the AT.

Cowen and Turner-Smith [20] propose that 'the social model of disability recognises that many people may not define themselves as disabled or in need of special equipment so they may not take up a service offered with the best of intentions'. Newell [17] points to current ATs not being fashionable, but impending demographic change is likely to produce a demand and need for more aesthetically pleasing products. 'This will favour those assistive technology designers who are the fastest to respond to the true needs and wants of the user'. Newell goes on to ask: -

- Can alarm call buttons be designed as a fashion accessory?

- Would remote controlled curtains with a beautiful control panel add to everyone's home?

\subsection{Assistive Technologies as social signifier}

In order to truly understand the desirability and acceptability of assistive systems, there is a need to explore the larger social relationships and environments in which they would be placed. Most ATs are purposely designed for the home, a culturally recognised 'private' space. Yet the home as 'private' is not a neat and tidy classification as certain spaces such as the hallway, living room and kitchen maybe open to non-resident family, friends and visitors. As such spaces of the home transcend the neat binary classification of public or private being both public and private. In analysis of consumption at home, Silva [21] showed how her female informants sought social inclusion through acts of material consumption of mainly domestic goods and media technologies, accumulating products that signified their family's social inclusion. The home becomes the site through which goods are viewed and by extension those within the home are classified by these goods.

Miller [22] proposes that our ability to 'read' objects helps determine their social appropriateness, but that reading may differ between gender and class. Therefore, an object may signify different meaning for a man then a woman. The same object maybe revered by one subject only to be ridiculed and parodied by another. One group may find an object acceptable because it is 'bright and cheerful', whilst another 'enshrines its sense of good design'. In effect the object itself becomes the source of struggles over interests. As such an objects reading may influence it's initial purchase, where social value overrides functional considerations.

Miller proposes that through the consumption of goods some sectors of the population are able to utilise objects in their creation of a sense of self. In contrast, other groups are forced to live with objects created through images of them held by a dominant sector of the population. Goods are largely symbols of wealth and fashion that often reflect wider social differentiation. If an item has a certain specification, it will be magnified when compared with goods that do not. Miller suggests that the goods specificity becomes intertwined with the user, so that the specific nature of the user is defined by the specific nature of the object. In comparison, goods designed for mass consumption are perceived to create close social networks, provide 'equalising and normative mechanisms promoting solidarity and sociability'.

Sociological readings of objects help us to understand the wider meanings that they may hold, especially for people who use objects of a specific nature, such as ATs as 
external add-on devices. Coleman [23] states that 'personal surroundings communicate strong messages about identity, social position and values, which makes meeting people's aspirations as important as functionality and problem solving, if not more so'. Hence, when considering the incorporating of ATs within the home, it can be argued that it is vitally important that the design of such technologies, how they look and fit within the domestic environment, one that is both public and private be considered as not only an aspect of aesthetic pleasure but also as a wider social signifier of who the user is, and even as a possible object of wider social inclusion.

\section{Inclusive Design as a Basis for Non-Stigmatic Design}

It is widely accepted within inclusive design discourse that a 'one size fits all' approach is implausible. People of varied ages, abilities, gender and social and cultural background, will desire products as varied as the population. Naess \& Ortsland [24] recognise that current ATs can be stigmatising as they often embody a 'neutral' or 'for all' aesthetic. Such a lack of styling prevents people projecting their desired self through the objects associated with them as 'no one wants to be a product of an assistive product, which embodies aesthetics few would accept given a choice'.

Cowen and Turner-Smith [20] state that 'to ensure relevant design and uptake of technology, older people have to be given power to influence development themselves. This may be through the interested involvement of industrial designers, but most effectively it will be by the financial power older people can exert.

With the rise in an older population, namely the 'baby-boomers', it is estimated that the demand for certain aesthetic in products aimed at this demographic will also increase. Current marketing terms such as the Yo-Yo (young old) and WOOF (well off old folk) identify such groups as lucrative markets of consumers who resist age identification in their product consumption. Cassim [25] suggests that as product and technology literate consumers they will use the same work or leisure related products but will require forms of enhanced functionality. Within these products they will desire 'inclusivity by stealth', that take into consideration declining physical, sensory and cognitive capabilities, 'but lacks aesthetic stigma' found in many assistive technologies 'that would single them out as old or disabled, for they view themselves as neither'.

\subsection{The "Go -steady" campaign}

Since 1969 the universal symbol of disability has been the pictogram of a stick figure in a wheelchair. This symbol has been used to indicate access to areas of the built environment such as ramps, parking spaces and toilets. However, this 'universal' symbol can be considered to not fully represent the population of people with disabilities, of whom it is estimated only 5\% use wheelchairs. Cassim (2007) [26] suggests that 'the subtlety and range of disability issues the pictogram aims to cover are ignored and the sign sets apart the population it aims to integrate. Indeed, Bichard et al (2006) [27] found that the designation of accessible toilets by the 'wheelchair' logo created tensions between users whose disability was visible and those whose 
disability was hidden (such as a colostomy or urostomy), yet required the facilities of the accessible cubicle.

This case study represents the output of the Design Business Association (DBA) Inclusive Design Challenge. An example of non-stigmatic design, it aims to raise awareness of problems of frailty, balance and mobility by a communications campaign based around assistance to people with mobility impairments and represented by an interlocking arrow motif (see Figure 3 below)

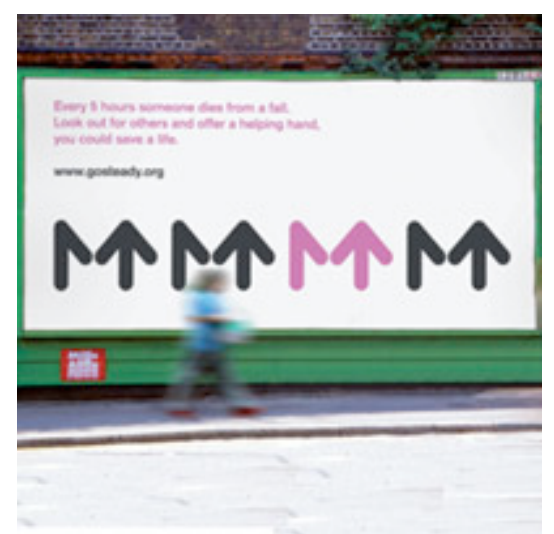

Fig. 3 This symbol set could be used on signage, labelling or media campaigns.

The design team at Wolff Olins found that the current symbol represented the extreme consequences of mobility loss. In doing so, it failed to communicate potential hazards and risks, and did not fully encapsulate all those who may be vulnerable including older people. In addition, it was felt the current symbol for disability 'stigmatises and isolates those to whom it currently applies' (Cassim, 2007) [26].

The design chosen was felt to 'speak to all' who may experience permanent or temporary mobility impairment, and can therefore be considered more inclusive of the population who may require extra levels of vigilance.

\section{Conclusions}

The NHS glasses case illustrates both the tension between `functionality` and aesthetics, and the related medical and social models. Perhaps more importantly, it also illustrates how functionality and aesthetics can be combined, and how this can be understood through the inclusive `bio-social model'. However, as Pullin suggests, this fortuitous re-molding of the glasses was not user driven, but rather driven by the more amorphous pushes and pulls of the market. The case suggests that the intervention in designing out stigma has to be more direct and focused.

As a starting point it can be argued that the process itself needs to be initially understood, as illustrated with Goffman and Miller, and the AT and toilet case studies. When the biosocial model is used, and the functionality/aesthetics balance addressed, the outcome is potentially increasingly richer, and importantly, less stigmatising for the users. This is illustrated in the last case concerning the 'GoSteady`work. 
This paper has highlighted the need to reconsider the relationship between functionality and aesthetics when designing products to old and disabled people. These aspects of design need not be mutually exclusive. Indeed, through the consideration of a more socially orientated model, both aspects can be successfully incorporated into the design process from the start.

This understanding will not obviously lead towards the creation of products of high functionality in popular aesthetic forms every time. It will however remind the designer of the importance of the relationship between functionality and aesthetics, and this in itself will lead to a more considered design process, and not one left to the 'invisible hand of the market.

\section{References}

1. Goffman, E (1963) Stigma: Notes on the Management of Spoiled Identity. PrenticeHill, New Jersey.

2. Bichard, J. J, Hanson, C. Greed (2005) Cognitive Aspects of Public Toilet Design. HCII Conference Proceedings, Las Vegas, Nevada.

3. Pullin, G. (2007) When Fashion Meets Discretion. INCLUDE 2007 Conference Proceedings, Royal College of Art, Helen Hamlyn Centre, London April $1^{\text {st }}-4^{\text {th }}$.

4. Lewis, J (2001) Vision for Britain: the NHS, the opticle industry and spectacle design 1946-1986. Dissertation, Royal College of Art, London.

5. Busch, A. (1991) From Stigma to Status: the specifications of spectacles in Metropolis, Vol 10 No. 8 pp 35-37.

6. World Health Organisation (1980) International Classification of Impairments, Disabilities and Handicaps. WHO, Geneva.

7. Imire, R. and P. Hall (2001) Inclusive Design: designing and developing accessible environments. Spon Press, London \& New York.

8. Hanson, J., M. Johnson \& J. Percival (2002) The Housing, Support and Care Needs of Older People. Final report for the Thomas Pocklington Trust, London.

9. Hanson, J. (2004) The Inclusive City: Delivering a more accessible urban environment through Inclusive Design. Proceedings of COBRA Royal Institute of Chartered Surveyors conference $7^{\text {th }}-8^{\text {th }}$ September.

10. Seldon, A. (2004) Changing Technology in Disabling Barriers - Enabling Environments, J. Swain, S. French, C. Barnes \& C.Thomas (Eds) Sage, London.

11. Davies, J., T. A. Hirschl \& M. Stack (1997) Integrated circuits, circuits of capital and revolutionary change in J. Davis, T. A. Hirschl \& M. Stack (Eds) Cutting Edge technology, Information, Capitalism and Social Revolution. Verso, London.

12. Finkelstein, V. (1980) Attitudes and Disabled People. World Rehabilitation Fund, New York.

13. Oliver, M. (1990) The Politics of Disablement. Macmillan, London.

14. Illich, I.D. (1973) Tools for Conviviality. Calder and Boyars, London.

15. Gleeson, B. (1999) Can technology overcome the disabling city? In R. Butler \& H.

Parr (Eds) Mind and Body Spaces: Geographies of Illness, Impairment and Disability. Routledge, London.

16. Cowen, D. \& A. Turner-Smith (1999) The role of assistive technology in alternative models of care for older people in Royal Commission on Long Term Care, Research Vol 2, Appendix 4, Stationary Office, London.

17. Newell, A. (2003) Inclusive Design or Assistive Technology in Inclusive Design; Design for the Whole Population, J. Clarkson, R, Coleman, S. Keates \& C. Lebon (Eds), Springer, London.

18. McCredie, C. \& A. Tinker (2005) The acceptability of assistive technology to older 
people from Ageing \& Society Vol 25 pp 91-110.

19. Hanson, J. (2005) The Housing and Support Needs of adults Aged 18-55 with Impaired Vision: A good practice guide. UCL, The Housing Corporation \& Thomas Pocklington Trust, London.

20. Cowen, D. \& A. Turner-Smith (1999) The role of assistive technology in alternative models of care for older people in Royal Commission on Long Term Care, Research Vol 2, Appendix 4, Stationary Office, London.

21. Silva, E (2000) The Politics of Consumption@Home, PAVIS Papers in Social and Cultural Research No. 1. Faculty of Social Sciences, The Open University.

22. Miller, D. (1987) Material Culture and Mass Consumption. Basil Blackwell, Oxford and Cambridge MA.

23. Coleman, R. (2001) Designing for our Future Selves in Universal Design Handbook, W.F.E. Preiser \& E. Ostroff (Eds). McGraw-Hill, New York.

24. Naess, I. \& Ortsland, T. (2005) Inclusive Mainstream Products. Conference proceedings INCLUDE 2005, Royal College of Art, Helen Hamlyn Research Centre, London.

25. Cassim, J (2004) Cross-market Product and Service Innovation - the DBA Challenge Example in Designing a More Inclusive World, S. Keates, J. Clarkson, P. Langdon \& P. Robinson (Eds). Springer, London.

26. Cassim, J. (2007) DBA Inclusive Design Challenge Winner - Wolff Olins in Innovate July 2007, Royal College of Art, London.

27. Bichard, J. J, Hanson, C. Greed (2006) 'Our Toilets; Access dilemmas in UK 'disabled' washrooms'. Conference presentation Association of American Geographers AGN, Chicago March. 